\title{
A previsão de perdas de terra através de erosão do solo sob vários usos de terra na área de colonização da Rodovia Transamazônica
}

Philip M. Fearnside ( $\left.{ }^{(}\right)$

\begin{abstract}
Resumo
Perdas de terra foram preditas como uma parte de um estudo maior destinado a produzir estimativas da capacidade de suporte para populações humanas em uma parte da área de colonizaçăo da Transamazônica. As medidas de erosão representam a baixa do nivel da superficie do solo, e por isso incluem a compactação do solo. Estimativas de mudanças de nível de terreno foram feitas em solos sob culturas anuais (arroz de sequeiro, milho, feijāo e mandioca), pimenta-do-reino, cacau, pastagen, capoeira e mata primária. Regressões foram desenvoividas para a previsão de perdas de terra, baseadas em tais variáveis, como declive e teor de argila no solo. As equações de previsão de mudança de nivel de terreno desenvolvidas foram usadas em simulaçōes de computador do agro-ecossistema dos colonos para estimativa de capacidade de suporte. Erosâo tem efeito na capacidade de suporte através do seu efeito sobre a fertilidade do solo, e por isso sobre produçöes das culturas.
\end{abstract}

\section{INTRODUÇÃO}

Uma área de colonização planejada na Rodovia Transamazônica perto de Altamira, Pará, oferece uma oportunidade única para u estudo de vários aspectos de agro-ecossistemas que foram estabelecidos pelos colonos. $\mathrm{O}$ estabelecimento rápido e em grande escala, ao longo da rede do rodovias pioneiras, ainda em expansão na Amazônia, faz com que a previsão dos danos devidos à erosão seja urgente. As estimativas de danos ao solo devidos à erosão se tornaram necessárias como uma parte de um estudo da capacidade de suporte humana em uma parte da área de colonização (Fearnside, 1978 e 1979a). A capacidade de sustentação depende da produção agrícola, a qual é influenciada pela fertilidade do solo, o qual, por sua vez, é atingido pela erosão. Simulações de computador foram feitas, modelando o agro-ecossistema, incluindo uma sub-rotina para previsão de erosão do solo, ou seja, neste caso, estimativas de mudança do nível do terreno. In formação de entrada sobre utilização da terra, declividade, solo e tempo foram gerados em outras partes do programa para reproduzir os padrões encontrados em dados de campo. As simulações são de tipo estocástico, incluindo as distribuições de probabilidade em torno das médias de muitos parâmetros importantes.

Pesquisas sobre erosão de solo na América Latina foram recentemente revisadas por Lal (1977), que não encontrou nenhum estudo de erosão na Amazônia brasileira. O único €studo além deste envolvendo erosão de que tomei conhecimento é o de Smith (1976: 112), o qual faz mensurações da baixa da superficie do solo em cinco quadras sob culturas anuais com declives entre 8 e $15 \%$. Durante um período de seis meses, nos quais $1.683 \mathrm{~mm}$ de chuva caíram na área, a superfície do solo baixou de 0,4 a $1,7 \mathrm{~cm}$. Advertências gerais dos perigos da erosão na Amazônia brasileira têm sidos feitas (p. ex.: Penteado, 1967: 359-81), mas nenhuma mensuração foi tomada. Para uso nas simulacões de capacidade de suporte, relações quantitativas tinham que ser estabelıcidas entre taxas de erosão e várias outras variáveis, preferivelmente com relações separadas sendo derivadas para cada um dos tipos de uso de terra encontrados na área de estudo (Fearnside, 1979b)

\section{MATERIAIS E MÉTODOS}

Durante dois anos de trabalho de campo (1974-1976), numa área de 23.600 ha, em volta da Agrovila Grande Esperança, a $50 \mathrm{~km}$ a oeste de Altamira, foram coletados dados para o estudo de capacidade de suporte, incluindo

i*) - Instituto Nacional de Pesquisas da Amazônia, Manaus. 
solo, declividade, utilização da terra e outras informações. As avaliações de erosão relatadas aqui foram feitas em 1975. Medidas foram feitas usando-se uma série de 705 estacas fixadas em 47 quadras de 15 estacas cada, abrangendo diferentes declividades e utilizações da terra. Foi tomado todo o cuidado na localização das quadras para minimizar a possibilidade de vandalismo ou cutros distúrbios humanos das estacas. As quadras foram fixadas, cobrindo o máximo de declives em cada uso de terra, com 5 quadras na floresta virgem, 5 quadras em capoeira, $5 \mathrm{em}$ roças de feijão, $11 \mathrm{em}$ arroz, $5 \mathrm{em}$ milho, 5 em mandioca, $5 \mathrm{em}$ pasto, $3 \mathrm{em}$ cacau e $3 \mathrm{em}$ pimenta-do-reino. Os declives das quadras no estudo variaram de 0 a $89 \%$.

As estacas medindo $1,9 \mathrm{~cm}(3 / 4$ de polegada de diâmetro) eram canos de plástico fixados no chão a uma profundidade de $40 \mathrm{~cm}$ (Fig. 1). Em cada quadra, as estacas foram arranjadas em 3 fileiras de 5 estacas cada, com aproximadamente 2 metros entre as estacas e 10 metros entre as fileiras. As fileiras estavam orientadas perpendicularmente em relação ao declive. As estacas das extremidades mediam 1 metro de comprimento, enquanto as do meio mediam $50 \mathrm{~cm}$. Cada estaca tinha um talho cortado horizontalmente e era alinhada exactamente com o nível da superfície do chão na hora da implantação da estaca. Um corte vertical também foi feito para marcar o centro de cada talho para facilitar as medidas. O talho era orientado para a direção lateral (ao longo da curva de nível). Os declives das quadras foram medidos percentualmente usando-se um clinômetro (Suunto). Estas medidas foram feitas para os comprimentos das quadras (20 metros) usando-se como ponto de visão as últimas estacas, de um metro de comprimento, das filas de cima e de baixo. Microrrevelo (declive de estacas) foi medido em cada estaca colocando-se o clinômetro num bloco de madeira de $30 \mathrm{~cm}$ orientado ao longo do declive mais alto da estaca. As medidas de erosão foram feitas medindo-se a distância do centro do taIho até à superfície do solo em cada estaca usando-se uma régua graduada em milímetros. Um perfil do solo foi tirado em cada quadra na hora da instalação usando-se um trado de solo de um metro. Amostras de fertilidade da superfície foram coletadas por ocasião da instalação e da medição: estas eram compostas de 15 subamostras com $0-20 \mathrm{~cm}$ de profundidade tiradas das vizinhanças de cada estaca. As análises do solo foram feitas pelo Centro de Pesquisa Agropecuária do Trópico Úmido (CPATU) em Bəlém. Os métodos de laboratório estão descritos por Guimarães et al. (1970). A compactação do solo foi medida em solo úmido usando-se um penetrômetro de mola com bico cônico. Dez medidas foram tomadas em cada estaca. A densidade do solo foi medida, removendo-se, aproximadamente, dois $\mathrm{kg}$ de solo de

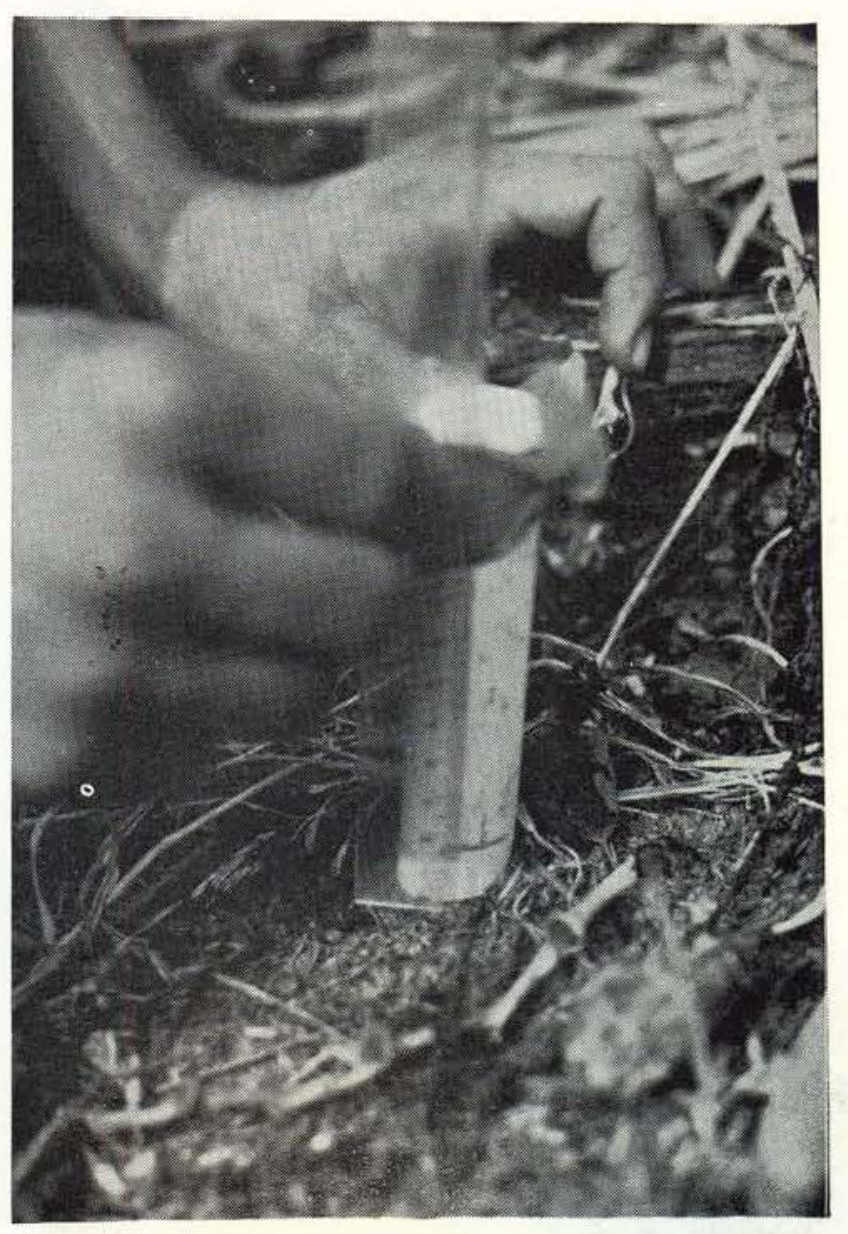

Fig. 1 - Estaca para medida de erosão mostrando uma baixa representativa na superfície do solo da ordem de um centímetro por ano em culturas anuais. Estacas foram colocadas em 47 quadras de 15 estacas cada para previsão de erosão com diferentes usos de terra e declives. 
$10 \mathrm{~cm}$ da camada superficial pela introdução de um cilindro de metal (com $7 \mathrm{~cm}$ de diâmetro) no solo várias vezes. As amostras de densidade eram secadas ao ar livre e pesadas em uma balança de mola com precisão de $5 \mathrm{~g}$.

Os lançamentos dos declives acima das quadras de erosão foram medidos, com medidas separadas sendo feitas se havia uma mudança perceptível no declive ou uma mudança no uso da terra.

Dados meteorológicos foram obtidos da estação meteorológica do governo mais perto da área de estudo que tinha dados registrados para cada dia. Usualmente, era a estação do CPATU localizada $23 \mathrm{~km}$ a oeste de Altamira, mas, às vezes, a estação do Departamento de Meteorologia, em Altamira, era a fonte de dados mais próxima existente.

O uso da terra foi designado para campos utilizando-se o uso da terra no período de máxima precipitação em um período de 24 horas.

As avaliações de erosão com quaisquer dos seguintes transtornos ou circunstâncias especiais foram excluídas das análises: 1) estacas pisadas (por animais ou homens); 2) estacas queimadas atingindo a marca; 3) nível do solo modificado por enxada; 4) solo nas proximidades da estaca forçado para cima pelo crescimento de raízes; 5) nível do solo perturbado por galinhas ou outros animais; 6) estaca em bueiro; 7) estaca em deposição debaixo de uma raiz; 8) estaca enterrada face à colheita de mandioca; 9) porcos na quadra de erosão; 10) nível da estaca modificado de outra maneira pelo homem; 11) nível do solo modificado de outra maneira pelo homem.

A manipulação dos dados e vários cálculos foram feitos usando-se uma série de programas FORTRAN feitos sob esse propósito (Fearnside, s.d.). As análises estatísticas foram feitas usando-se o Michigan Interactive Data Analysis System (Sistema de Análise de Dados Interativa Michigan) ( Fox \& Guire, 1976). Os resíduos de todas as regressões foram examinados, para verificar-se a falta de dependência junto às magnitudes das variá. veis independentes.

\section{REsultados}

As características das quadras de erosão e da área de estudo estão resumidas nas Tabelas 1 e 2. Uma vez que muitas das variáveis seriam esperadas como boas prognosticadoras de erosão, baseadas em equações de perdas de solo desenvolvidas em outras partes do mundo (revistas por Hudson, 1977). são conhecidas somente ao nível da quadra, em vez de estacas individuais, as regressões que incluem estas variáveis que só puderam ser efetuadas incluinda-se estas variáveis usando-se dados ao nível da quadra onde o tamanho da amostra permite. Estão incluídos: conteúdo de argila no solo; densidade do solo; médias da quadra para compactação (medidas do penetrômetro); precipitação no intervalo de observação; precipitação enquanto o solo era nu ou sob culturas anuais, e declive da quadra. Os lançamentos dos declives foram também considerados em caráter a nivel de quadra, ainda que três valores ligeiramente diferentes se refiram a estacas dentro de cada quadra. A precipitação máxima em 24 horas foi a mesma para todas as quadras do ano, para o qual estas análises se referem. A informação ao nível de estaca inclui erosão à estaca, declive à estaca, e média de compactação de solo à estaca.

Regressões separadas foram efetuadas com dados de culturas anuais individuais, todas revelando semelhantes relações de erosão e declive. Todas as quadras, tanto em culturas anuais quanto em solo nu (definido como com menos de 60 dias após a colheita) no tempo de precipitação máxima, em um período de 24 horas, foram ajuntadas para obter-se a seguinte regressão:

$$
Y=0,164 \mathrm{~A}+1,88 \times 10^{-3} \mathrm{~B}+1,43
$$

onde: $Y=$ erosão da quadra $(\mathrm{mm} / \mathrm{ano})$

$$
\begin{aligned}
A= & \text { declive da quadra }(\%) \\
B= & \text { chuva durante o período de solo } \\
& \text { nu ou em cultura anual }(\mathrm{mm})
\end{aligned}
$$

( $P<0,0001, r=0,89, r^{2}=0,79$, Erro padrão $=2,13, N=17$ médias de quadra). As variáveis não incluídas na regressão foram estatisticamente não-significativas. 
TABELA 1 - Características das quadras de erosão para quadras em culturas anuais no período de precipitação máxima

\begin{tabular}{|c|c|c|c|c|}
\hline ITEM & UNIDADES & MÉDIA & $\begin{array}{l}\text { DESVIO } \\
\text { PADRÄO }\end{array}$ & $\begin{array}{l}\mathrm{N} \cdot{ }^{\circ} \text { DE } \\
\text { OBSERVAÇÕES }\end{array}$ \\
\hline Densidade do sola & $\mathrm{g} / \mathrm{cm}^{3}$ & 1,237 & 0,192 & 18 \\
\hline Comprimento do primeiro declive acima da quadra & metros & 52,1 & 71,2 & 18 \\
\hline Comprimento do segundo declive acima da quadra & metros & 86,2 & 35,9 & 11 \\
\hline Comprimento do terceiro declive acima da quadra & metros & 98,0 & 46,6 & 3 \\
\hline Comprimento total dos declives acima da quadra & metros & 84,8 & 99,2 & 18 \\
\hline Argila total do solo & $\%$ & 33,5 & 12,7 & 17 \\
\hline Precipitação total no intervalo de medida & $\mathrm{mm}$ & $1.406,9$ & 210,7 & 18 \\
\hline Precipitação máxima em 24 horas & $\mathrm{mm}$ & 86,0 & - & 18 \\
\hline $\begin{array}{l}\text { Precipitação enquanto o solo esteja nu ou sob cul- } \\
\text { turas anuais }\end{array}$ & $\mathrm{mm}$ & 891,0 & 544,2 & 17 \\
\hline
\end{tabular}

TABELA 2 - Caracteristicas das quadras de erosão para todas as quadras

\begin{tabular}{lcccc}
\hline ITEM & UNIDADES & MÉDIA & $\begin{array}{c}\text { DESVIO } \\
\text { PADRÃO }\end{array}$ & $\begin{array}{c}\text { N. DE } \\
\text { OBSERVAÇÕES }\end{array}$ \\
\hline Densidade do solo & g/cm & 1,188 & 0,148 & 47 \\
Comprimento do primeiro declive acima da quadra & metros & 47,9 & 49,0 & 47 \\
Comprimento do segundo declive acima da quadra & metros & 61,3 & 40,9 & 27 \\
Comprimento do terceiro declive acima da quadra & metros & 79,0 & 39,0 & 8 \\
Comprimento total dos declives acima da quadra & metros & 74,8 & 75,4 & 47 \\
Argila total do solo & $\%$ & 34,2 & 12,8 & 45 \\
Precipitação total no, intervalo de medida & mm & $1.408,2$ & 182,9 & 41 \\
Precipitação máxima em 24 horas & $\mathrm{mm}$ & 86,0 & - & 47 \\
\hline
\end{tabular}

Para a erosão sob pimenta-do-reino, medidas de estacas individuais foram usadas. A equação de regressão obtida foi :

$$
Y=0,712 A+6,05
$$

onde: $Y=$ erosão da estaca $(\mathrm{mm} / \mathrm{ano})$

$$
A=\text { declive da estaca }(\%)
$$

$\left(\mathrm{P}<0,001, r=0,55, r^{2}=0,30\right.$, erro padrão $=6,10, \mathrm{~N}=39$ estacas).

A erosão sob outros usos da terra não pôde ser prevista por regressões usando-se os dados disponíveis. A erosão média da estaca em cacau novo foi $10,0 \mathrm{~mm} /$ ano (desvio padrão $=8,3, N=40$ estacas). A erosão média de estaca em ervas daninhas (definida como alqueive de dois a oito meses inclusive) foi de $8,1 \mathrm{~mm} /$ ano (desvio padrão $=5,4, \mathrm{~N}=56$ estacas). Erosão média de estaca em capoeira (definida como alqueive superior a oito meses) foi de $6,9 \mathrm{~mm} / \mathrm{ano}$ (desvio padrão $=8,7, \mathrm{~N}=68$ estacas). Erosão média de estaca em pastagem foi de 6,7 $\mathrm{mm}$ /ano (desvio padrão $=11,8, \mathrm{~N}=105$ estacas). Erosão média de estaca em floresta virgem foi de $7,5 \mathrm{~mm} /$ ano (desvio padrão = $5,1, N=75$ estacas). As médias de erosão de estaca para ervas daninhas, capoeira, pastagem, e floresta virgem não foram significativamente diferentes, porém, as variâncias o são $(\mathrm{P}<0,0001, \mathrm{~F}=25$, $\mathrm{gl}=3 ;$ 144.710).

Os declives das estacas $(30 \mathrm{~cm}$ ao redor de cada estaca) podem ser produzidos de declive da quadra de erosão total (aproximadamente 20 metros) usando a seguinte equação:

$$
\mathrm{Y}=0,462 \mathrm{~A}+3,13
$$

onde: $Y=$ declive da estaca $(\%)$ 


$$
A=\text { declive da quadra }(\%)
$$

( $P<0,001, r=0,89, r^{2}=0,80$, erro padrão

$=4,94, \mathrm{~N}=705$ estacas. 47 quadras, $\mathrm{gl}$ $=45$ ).

\section{Discussão}

As avaliações de erosão usadas aqui, baseadas em mudanças no nível da superfície do solo, realmente incluem os resultados de compactação do solo assim como também erosão verdadeira. Medidas de erosão através de açudes e bacias de sedimentação teriam evitado este problema, mas teriam tido a infeliz conseqüência de reduzir a quantidade de dados coletáveis tanto sobre erosão quanto sobre outros aspectos do agro-ecossistema. O método da estaca entalhada provou-se adequado para o uso na previsão de mudanças na fertilidade do solo, embora métodos mais aperfeiçoados sejam necessários para outros propósitos. A maioria dos rebaixamentos da superfície do solo observada supõe-se devido à erosão em vez de compactação, especialmente para aqueles usos de terra, tais como culturas anuais, para as quais erosão é mais forte.

É preferível usar declive de quadra ao declive de estaca para previsão de erosão, embora declives de estaca sejam usados no caso de usos de terra onde as limitações dos dados impedirem o uso de caracteres ao nivel da quadra. No sentido de obterem-se resultados mais gerais que puderem ser aplicados com maior confiança em outras áreas, necessitar-se-ia uma maior espectro de precipitaçōes totais e intensidades de precipitações. Dados meteorológicos específicos do local mais minuciosos, especialmente de intensidade de precipitação, permitiriam indubitavelmente previsões mais poderosas a serem desenvolvidas $O$ desaparecimento de uma remessa de pluviômetros impediu isto no caso do presente estudo.

Embora os conteúdos de areia e argila do solo variem consideravelmente $€$ ntre quadras, uma maior espectro de valores, junto com um tamanho de amostra maior, provavelmente permitiriam a inclusão deste fator nas equações de regressão. Maiores porcentagens de argila seriam esperadas de modo a resultar em maior erosão pela redução da percolação da água e conseqüentemente aumento do escoamento. Compactação do solo teria o mesmo efeito, e uma maior espectro de valores e mais dados provavelmente permitiriam a inclusão disto também. Tais aumentos no núməro de variáveis tornariam a extensão dos cálculos para outras áreas mais seguras.

$\mathrm{Na}$ área da Rodovia Transamazônica, a erosão resulta na redução de fertilidade do solo. Os horizontes mais profundos em perfis do solo na área têm fertilidade menor que a superfície (Falesi, 1972; Fearnside, 1978). Muita da fertilidade acessivel para culturas vem das cinzas produzidas pela queimada, que é também removida pela erosão. A possibilidade de a erosão aumentar a fertilidade do solo pela exposição de material menos exposto às intempéreis (Sanchez \& Buol, 1975) não se aplica aqui.

A questão de erosão em pastagem é de particular importância, dado o rápido aumento da quantidade de pastagem em toda parte da Amazônia brasileira. Instituições influentes no planejamento de futuros esquemas de desenvolvimento da Amazônia brasileira acreditam que a pastagem oferece completa proteção contra a erosão (IPEAN, 1974: 43).

Vários pesquisadores têm encontrado erosão em pastagens tropicais. Daubernmire (1972: 50) verificou-se que pastagem de Hyperrhenia rufa na Costa Rica com 1.900 $\mathrm{mm} /$ ano de precipitação e declive de $9 \%$ mostrou $11 \mathrm{~cm}$ de erosão durante $o$ período de vida das plantas mais velhas em uma pastagem com 22 anos de idade. Perdas por erosão foram estimadas, examinando-se as diferenças em altura entre superfícies seixosas dentro de tufos de capim quando comparadas com as áreas entre tufos. Uma vez que os tufos de capim podem não ser tão velhos quanto as pastagens propriamente ditas, a taxa de erosão pode ter sido mesmo maior que os cinco $\mathrm{mm} /$ ano que estas medidas indicam. Comparações de taxas de erosão em pastagem e floresta virgem foram feitas no Peru Oriental por Scott (1975: 127), que usou diques e bacias de sedimentação para medir 
a erosão. Ele encontrou alguma erosão em pastagem e nenhuma em floresta virgem, embora ele não dê os valores em sua publicação. A ausência de diferença significativa na erosão média em pastagens e floresta virgem encontrada no presente estudo não significa, de modo algum, que não ocorre erosão em pastagens. A variância na erosão em pastagem é extremamente alta, sendo o valor do desvio padrão quase duas vezes o valor do médio. Muitas estacas mostraram considerável erosão em pastagem. A formação de sulcos pode também ser um grave problema em pastagem, especialmente porque o capim de pastagem mais comumente plantado (Panicum maximum) cresce em tufos separados com espaço nus entre si.

\section{CONCLUSÕES}

Os resultados deste estudo indicam que a erosão apresenta uma ameaça potencial à fertilidade do solo na área de colonização da Rodovia Transamazônica do Brasil. Erosão, ou mudança de nível de terreno, é pior em culturas anuais, e também é muito séria em pimenta-do-reino. Erosão pode também ser um problema potencial em pastagem, especialmente erosão por formação de sulcos. Equações têm sido desenvolvidas para a previsão de erosão laminar para uso na previsão de mudanças na fertilidade do solo como uma parte de uma simulação do agro-ecossistema dos colonos.

\section{Agradecimentos}

O financiamento para o projeto do qual este trabalho é uma parte vem de National Science Foundation Dissertation Improvement Grant GS 42869, uma bolsa de estudo pré-doutorado do Resources for the Future, duas bolsas de estudo do Institute for Environmental Quality da University of Michigan, e do Programa do Trópico Úmido do Conselho Nacional de Desenvolvimento Científico e Tecnológico. Agradece-se também à Ford Foundation e ao Conselho Nacional de Desenvolvimento Científico e Tecnológico, por ter pos- sibilitado a apresentação destes dados no V International Symposium of Tropical Ecology, Kuala Lumpur, Malásia 16-23 de abril de 1979. Nenhum dos pontos de vista expressos são de responsabilidade das organizações que têm apoiado o projeto.

\section{SUMMARY}

Soil erosion losses were predicted as a part of a larger study aimed at producing estimates of human carrying capacity for a part of the Transamazon Highway Colonization Area of Brazil. Erosion measurements were made under annual crops (upland rice, maize, beans, and manioc), black pepper, cacao, pasture, second growth, and virgin forest. Measurements are of the drop in soil surface levels, and therefore include soil compaction. Regressions were developed for prediction of erosion based on such variables as slope and soil clay content. The erosion prediction equations developed were used in computer simulations of the colonists agroecosystem for carrying capacity estimation. Erosion affects carrying capacity through its effect on soil fertility and thereby crop yields.

\section{BIBLIOGRAFIA}

DAUBENMIRE, $R$.

1972 - Some ecologic consequences of converting forest to savana in northwestern Costa Rica. Tropical Ecology, 13: 31-51.

FALESI, I.C.

1972 - Solos da Rodovia Transamazônica. Instituto de Pesquisa Agropecuária do Norte (IPEAN) Boletim Técnico, (55): 1-196.

FEARNSIDE, P.M.

1978 - Estimation of Carrying Capacity for Human Populations in a part of the Transamazon Highway Colonization Area of Brazil. Tese de doutoramento da Universidade do $\mathrm{Mi}$ chigan, University Microfilms, Ann Arbor. Michigan. 624p.

1979a - A Simulação de Capacidade de Suporte para Populações Humanas Agrícolas nos Trópicos Úmidos: Programa de Computador e Documentação. (Mimeografado) 546p.

$1979 \mathrm{~b}$ - The prediction of soil erosion losses under varicus land uses in the Transamazon Highway Colonization Area of Brazil. (no prelo: Proceedings of the 5th International Symposium of Tropical Ecology, 16-21 April, 1979, Kuala Malaysia, International Society for Tropical Ecology (ISTE), Varanasi, Uttar Pradesh, India).

s.d. - Pacote para Manejo de Dados para Estimativa de Capacidade de Suporte nos Trópicos Úmidos: Programa de Computador e Documentação. (Em preparação). 
Fox, D.J. \& GUIRE, K.E.

1976 - Documentation for MIDAS. 3. ed. Ann Arbor. University of Michigan Statistica! Research Laboratory, 203p.

Guimarães, G. de; Bastos, J.B. \& Lopes, E. de C.

1970 - Métodos de Análise Física, Química e Ins. trumental de Solos. IPEAN, Série: Química de Solos, 1 (1): 108p.

HUDSON, N.W.

1977 - The factors determining the extent of soil erosion p. 11-16 In: Greenland, D.J. \& Lal, R. (Compiladores) Soil Conservation and Management in the Humid Tropics. John Wiley \& Sons, New York, 283p.

IPEAN

1974 - Solos da Rodovia Transamazônica: Trecho Itaituba-Rio Branco; Relatório Preliminar. EMBRAPA-IPEAN, Belém. 53p.

LAL, R.

1977 - Review of soil erosion research in Latin America. p. 231-40 In: Greenland, D.J. \& Lal, R. (Compiladores) Soil Conservation and Management in the Humid Tropics New York. John Wiley \& Sons, 283p.

PENTEAdo, A.R.

1967 - Problemas de Colonização e de Uso da Ter ra na Região Bragantina do Estado do Pará Belém. Universidade Federal, 488p.

SANCHEZ, P.A. \& BUOL, S.W.

1975 - Soils of the tropics and the world food crisis. Science, 188: 598-603.

ScotT, G.A.J.

1975 - Soil profile changes resulting from the conversion of forest to grassland in the Montaña of Peru. Great Plains-Rocky Mountain Geographical Journal, 4: 124-30.

SмITH, N.J.H.

1976 - Transamazon Highway: a Cultural-Ecological Analysis of Colonization in the Humid Tropics. Tese de doutoramento da Universidade de California, Berkeley, 372p.

(Aceito para publicação em 11/10/79) 